\title{
Mucoid Pseudomonas aeruginosa Resists Nonopsonic Phagocytosis by Human Neutrophils and Macrophages
}

\author{
DAVID A. CABRAL, BERNADETTE A. LOH, AND DAVID P. SPEERT \\ Departments of Pediatrics [D.A.C., B.A.L., D.P.S.] and Microbiology [D.P.S.], University of British Columbia \\ and the Division of Infectious Diseases, British Columbia's Children's Hospital [D.A.C., B.A.L., D.P.S.], \\ Vancouver, British Columbia, Canada
}

\begin{abstract}
Mucoid Pseudomonas aeruginosa is an important respiratory pathogen in patients with cystic fibrosis, and once acquired is virtually impossible to eradicate. Although mucoid $P$. aeruginosa is generally believed to be resistant to phagocytosis, the mechanism is not understood fully. We studied the nonopsonic phagocytosis by human neutrophils or macrophages of eight mucoid/nonmucoid $\boldsymbol{P}$. aeruginosa pairs (three isogenic and five "wild-type"). Mucoid strains were relatively resistant to nonopsonic phagocytosis but the nonmucoid types were phagocytosis-susceptible as assessed by visual inspection and chemiluminescence assays. The mucoid and nonmucoid variants had equal numbers of pili but different surface characteristics as determined by biphasic partitioning in polyethylene glycol and dextran. The mucoid exopolysaccharide of mucoid strains appears to alter the surface characteristics of $P$. aeruginosa thereby rendering them resistant to nonopsonic phagocytosis. The resistance of mucoid variants of $P$. aeruginosa to nonopsonic phagocytosis may provide a survival advantage to these bacteria early in the course of pulmonary infection before opsonic antibody and complement are present in respiratory secretions. (Pediatr Res 22: 429-431, 1987)
\end{abstract}

\section{Abbreviations}

CF, cystic fibrosis

PEG, polyethylene glycol

PMN, polymorphonuclear leukocyte

MQ, monocyte-derived macrophage

CL, chemiluminescence

M, mucoid

In patients with CF, Pseudomonas aeruginosa is the most prevalent respiratory pathogen and colonization is often associated with severe pulmonary disease (1). Mucoid $P$. aeruginosa ultimately infects most CF patients and once present is virtually impossible to eradicate (1). Persistence of mucoid $P$. aeruginosa in the CF lung has been attributed to resistance to opsonindependent phagocytosis (2) and enhanced adherence to tracheal epithelium (3).

We have observed previously that certain nonmucoid strains of Pseudomonas are susceptible to nonopsonic phagocytosis (4);

Received February 25, 1987; accepted May 11, 1987

Correspondence Dr. David P. Speert, Division of Infectious Diseases, Research Centre, 304-950 West 28th Avenue, Vancouver, B.C. V5Z 4H4, Canada.

Supported by grants to DPS from the Canadian Cystic Fibrosis Foundation and the Medical Research Council of Canada. this process is correlated with bacterial piliation and hydrophobicity (5). The purpose of this study was to investigate the susceptibility to nonopsonic phagocytosis of mucoid $P$. aeruginos $a$ and to determine the role of bacterial surface characteristics in the process.

\section{MATERIALS AND METHODS}

Bacterial strains. Mucoid (M) P. aeruginosa strains P-1, C-46, and $C-91$ were cultured from the sputum of patients with $C F$. The spontaneous nonmucoid laboratory revertants have been described previously (5). The $\mathrm{M}$ and nonmucoid variants within each pair were of identical serotype. $M$ variants were readily distinguished from nonmucoid by colonial morphology (6). Five additional "wild" $M$ and classic (nonmucoid) pairs were cultured from the sputum of five separate patients with $\mathrm{CF}$ and were frozen after only one laboratory passage. Bacterial piliation was assessed by electron microscopy with negative staining as described previously (5). Bacteria were stored at $-70^{\circ} \mathrm{C}$ in MuellerHinton broth with dimethyl sulfoxide and used as seeds for each experiment. For phagocytosis experiments, bacteria were grown on Mueller-Hinton agar at $35^{\circ} \mathrm{C}$ for $18 \mathrm{~h}$, harvested with a sterile swab, washed thrice in phosphate-buffered saline, $\mathrm{pH} 7.4$ and adjusted spectrophotometrically to $10^{\circ} / \mathrm{ml}$. For phase partitioning experiments, the bacteria were prepared identically except that the third wash was in deionized water. After this preparation, $\mathrm{M}$ exopolysaccharide could still be detected on the surface of $\mathrm{M}$ strains by enzyme-linked immunoabsorbent assay (7).

Assessment of phagocytosis. PMN and M $\emptyset$ were obtained as described previously (5). Pulmonary alveolar macrophages were obtained by bronchial lavage from healthy adult volunteers. The cells were kindly provided by Dr. Raja Abboud (Department of Medicine, University of British Columbia). In all cases the cells were $>95 \%$ viable as assessed by trypan blue dye exclusion. The pulmonary alveolar macrophages were adjusted to a concentration of $10^{7} / \mathrm{ml}$ and cultured with $13 \%$ fresh human serum in Teflon beakers at $37^{\circ} \mathrm{C}$ in a humidified $\mathrm{CO}_{2}$ incubator. The cells were harvested after overnight culture and prepared exactly as described for the $M \varphi(8)$.

Phagocytosis by PMN and by macrophages was determined by visual inspection of stained smears $(4,5)$ and by luminolenhanced CL (4) as described previously. Phagocytosis was expressed as the average number of bacteria phagocytized per PMN or as the percentage of macrophages with $<6,6-19$, or $>19$ ingested bacteria. CL was expressed as 1) maximum response, 2) time to peak, and 3) area under the curve. All experiments were repeated on at least 2 separate days with leukocytes from different donors. Differences in susceptibility to phagocytosis among strains were consistent from day to day but the phagocytic capacity of leukocytes from different donors or the same donor 
on different days varied markedly. Therefore results are expressed for individual experiments. The reported data are typical of experiments from all other days.

Assessment of bacterial surface characteristics. Bacterial surface forces were assessed as described previously (5) using a two polymer biphasic partition system composed of dextran and PEG. Data were expressed as the percentage of bacteria added to the system that were recovered from the PEG phase.

Statistics. Phagocytosis data were assessed by analysis of variance. The bacteria per PMN data were transformed to square roots (4) so that statistical inference based on the normal distribution would be valid. Differences were considered significant if the simultaneous $p$ value based on Bonferroni's method for all tests in a particular experiment was less than 0.05 .

\section{RESULTS}

Bacterial piliation was assessed by electron microscopy (Table 1 ); for each of the three isogenic pairs the $M$ and nonmucoid variants had an equal number of pili (P-1, 1-5 pili; C-46, 0-1 pili and C-91, 1-5 pili per bacterium). The nonmucoid variants of all three strains were phagocytized well by PMN in the absence of serum (Table 1). For strains P-1 and C-46, there was significantly better phagocytosis by PMN of the nonmucoid than the mucoid variant ( $p<0.0001$ for each). There was no difference in the uptake of the isogenic variants of strain C-91 by PMN. For all three pairs, there was substantially better phagocytosis by $M \emptyset$ of the nonmucoid than the mucoid variants. Because of a dearth of pulmonary alveolar macrophages, phagocytosis of only two isogenic pairs was studied. For both $\mathrm{P}-1$ and C-46, phagocytosis of the nonmucoid exceeded that of the mucoid variant. "Wild type" mucoid and classic (nonmucoid) P. aeruginosa were cultured from the sputum of five patients with CF. In each case, the classic strain was more susceptible than the mucoid colonial type to nonopsonic phagocytosis by human $\mathbf{M} \emptyset$ (Table 2).

Neutrophhil CL was studied as another measure of phagocytosis. Both mucoid and nonmucoid isogenic variants of all three strains induced CL responses (Table 1). A typical CL curve is shown in Figure 1. Neither the maximum CL response nor the area under the curve accurately reflected the degree of phagocytosis as determined by visual inspection. However, for each strain, the CL induced by the nonmucoid variant peaked earlier than with the mucoid. Thus as we have shown previously (5), time to peak CL response appeared to be the only parameter that accurately predicted the degree of phagocytosis of unopsonized $P$. aeruginosa; strains that induced the earliest peak responses were the best phagocytized.

Hydrophobic and electrostatic forces appear to play a critical

Table 1. Phagocytosis of three isogenic pairs of $M$ and nonmucoid (NM) P. aeruginosa by different types of human phagocytic cells

\begin{tabular}{|c|c|c|c|c|c|c|c|c|}
\hline & & \multirow{3}{*}{$\begin{array}{l}\text { Pilia- } \\
\text { tion }\end{array}$} & & & & \multicolumn{3}{|c|}{ Chemiluminescence } \\
\hline & & & \multicolumn{3}{|c|}{ Phagocytosis } & $\underset{\text { muxi- }}{\text { Maxi- }}$ & T. & $\begin{array}{l}\text { Area } \\
\text { under }\end{array}$ \\
\hline \multicolumn{2}{|c|}{ Strain } & & PMN & $\mathbf{M} \varphi$ & PAM* & cpm) & $(\min )$ & curve \\
\hline P1 & $\mathbf{M}$ & $++\ddagger$ & $0.05 \S$ & $5 \|$ & 0 & 28 & 113 & 2704 \\
\hline P1 & NM & ++ & 12.5 & 61 & 24 & 248 & 49 & 19472 \\
\hline C91 & $\mathbf{M}$ & ++ & 22.0 & 11 & & 75 & 61 & 5472 \\
\hline C91 & NM & ++ & 22.0 & 52 & & 91 & 37 & 6768 \\
\hline $\mathrm{C} 46$ & $\mathbf{M}$ & + & 0.8 & 0 & 11 & 185 & 129 & 15376 \\
\hline $\mathrm{C} 46$ & NM & + & 44.0 & 100 & 86 & 226 & 33 & 14816 \\
\hline
\end{tabular}

* Human pulmonary alveolar macrophage.

$\dagger$ Time of peak chemiluminescence.

$\$+, 0-1$ pili/bacterium;,$++ 1-5$ pili per bacterium.

$\S$ Average number of bacteria in each of $100 \mathrm{PMN}$ counted.

|| Percentage of macrophages with 20 or more bacteria ingested.
Table 2. Phagocytosis of "wild-type" $P$. aeruginosa strains of $M$ and classic colonial morphotypes by human monocyte-derived macrophages

\begin{tabular}{|c|c|c|c|c|c|c|c|c|}
\hline \multirow[b]{3}{*}{ Patient } & \multirow[b]{3}{*}{ Strain } & \multirow{3}{*}{$\begin{array}{c}\text { Colonial } \\
\text { type }\end{array}$} & \multicolumn{6}{|c|}{ Phagocytosis* } \\
\hline & & & \multicolumn{3}{|c|}{ Experiment 1} & \multicolumn{3}{|c|}{ Experiment 2} \\
\hline & & & $<6$ & $6-19$ & $>19$ & $<6$ & $6-19$ & $>19$ \\
\hline \multirow[t]{2}{*}{ A } & $\mathrm{C} 1210 \mathrm{M}$ & M & 100 & 0 & 0 & 100 & 0 & 0 \\
\hline & $\mathrm{C} 1212 \mathrm{C}$ & classic & 70 & 23 & 7 & 25 & 35 & 40 \\
\hline \multirow[t]{2}{*}{ B } & $\mathrm{C} 1628 \mathrm{M}$ & M & 100 & 0 & 0 & 98 & 2 & 0 \\
\hline & $\mathrm{C} 1745 \mathrm{C}$ & classic & 16 & 33 & 51 & 6 & 24 & 70 \\
\hline \multirow[t]{2}{*}{$\mathrm{C}$} & $\mathrm{C} 2012 \mathrm{M}$ & & 100 & 0 & 0 & 100 & 0 & 0 \\
\hline & C2003C & classic & 76 & 23 & 1 & 69 & 30 & 1 \\
\hline \multirow[t]{2}{*}{ D } & C1900M & M & 15 & 47 & 38 & 100 & 0 & 0 \\
\hline & C1901C & classic & 0 & 1 & 99 & 0 & 11 & 89 \\
\hline \multirow[t]{2}{*}{ E } & $\mathrm{C} 1518 \mathrm{M}$ & $\mathbf{M}$ & 61 & 36 & 3 & 53 & 38 & 9 \\
\hline & $\mathrm{C} 1519 \mathrm{C}$ & classic & 7 & 51 & 42 & 3 & 7 & 90 \\
\hline
\end{tabular}

* Percent of macrophages which have ingested number of bacteria indicated.

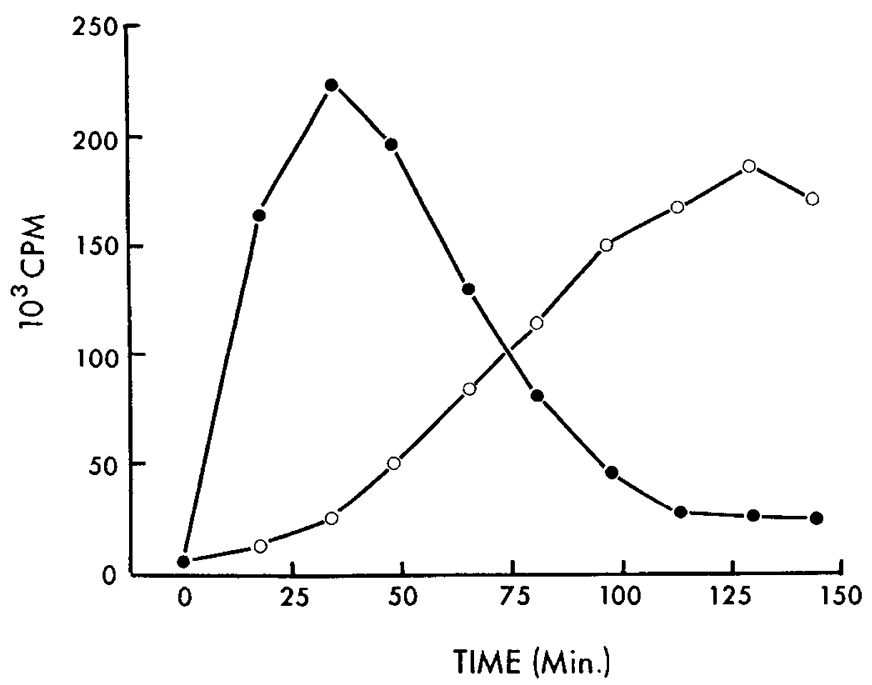

Fig. 1. CL response of human PMN phagocytizing isogenic variants of $P$. aeruginosa strain $\mathrm{C}-46(\mathrm{O}$, mucoid; $\bullet$, nonmucoid).

role in bacterium-phagocyte interactions (9). We therefore evaluated surface characteristics of the different $P$. aeruginos $a$ isolates in order to understand how mucoid variants resist phagocytosis. PEG/dextran partitioning of $\mathrm{M} /$ nonmucoid isogenic pairs were evaluated simultaneously and experiments were repeated on separate days (Figure 2). In every case, nonmucoid variants collected in the PEG phase to a greater extent than the M. Strain C-91M (the only $\mathrm{M}$ isolate susceptible to phagocytosis by PMN) collected in the PEG phase to a greater extent than the other M isolates.

\section{DISCUSSION}

Nonopsonic phagocytosis may play a critical role in host defense of the lung early in the course of bronchopulmonary infection prior to the development of an inflammatory response. Such may be the case in patients with $C F$ during the brief interlude between oropharyngeal colonization and lower respiratory tract contamination by $P$. aeruginosa. We have demonstrated previously that nonmucoid strains of $P$. aeruginosa from 


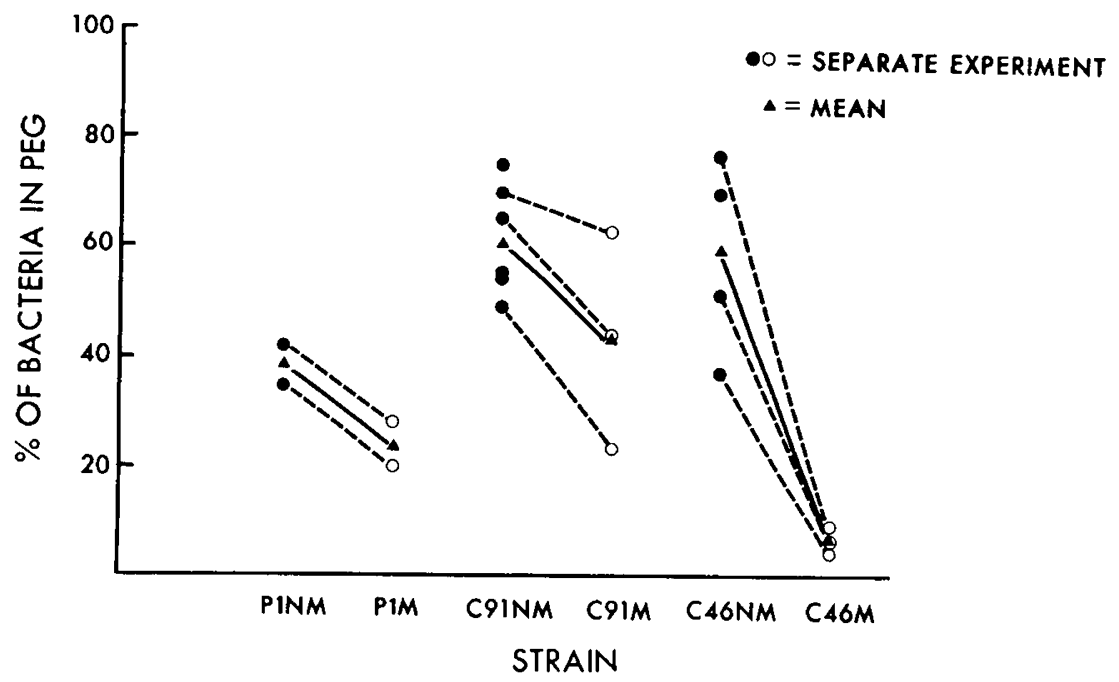

Fig. 2. Biphasic partitioning of $P$. aeruginosa $\mathrm{M}$ and nonmucoid isogenic pairs. $\bullet$ (nonmucoid) and $\bigcirc$ (mucoid) are results from individual experiments. Dotted line joins data from individually paired experiments and the solid line joins mean values from all experiments.

CF patients are frequently serum sensitive and susceptible to phagocytosis by human PMN and macrophages in the absence of serum (4). This process of nonopsonic phagocytosis, which is correlated with bacterial piliation, appears to depend on hydrophobic interactions with phagocytic cells; highly hydrophobic bacteria are phagocytized to a greater extent than less hydrophobic bacteria (5).

CF patients are often colonized initially with nonmucoid strains of Pseudomonas; in most cases these strains subsequently convert to the mucoid phenotype that is typical of "CF isolates." Although the reason for this phenotypic switch has not been determined, it is possible that production of the $\mathrm{M}$ exopolysaccharide provides a survival advantage for these bacteria. The $M$ exopolysaccharide is antiphagocytic $(10,11)$; $\mathrm{M}$, serum-resistant strains are relatively resistant to opsonic phagocytosis (2). M $P$. aeruginosa also adhere better to tracheal epithelial cells than do the nonmucoid variants (3). In addition to these potential survival advantages conferred by the $M$ phenotype, $M$ strains appear to be relatively resistant to nonopsonic phagocytosis.

$P$. aeruginosa $\mathrm{M}$ exopolysaccharide probably modulates bacterium-phagocyte interactions by altering the balance of electrostatic and hydrophobic surface forces. The polysaccharide is a well-hydrated negatively charged polyuronic acid which could enhance electronegative repulsive forces between bacterium and phagocyte. Pili may enhance phagocytosis of some strains by extending "hydrophobic bridges" across the electrostatic barrier between cells. Elaboration of large amounts of $M$ exopolysaccharide could physically abrogate this effect. In the present study, we demonstrated that $\mathbf{M}$ strains have different surface characteristics than their nonmucoid isogenic revertants as demonstrated by $\mathrm{PEG} /$ dextran partitioning and are relatively resistant to phagocytosis.

There are probably many bacterial and nonbacterial factors which contribute to both cell surface hydrophobicity and other surface phenomena and thereby modulate bacterium-phagocyte interactions. Pili are hydrophobic but do not appear to be the sole determinant of bacterial hydrophobicity. P. aeruginosa strain PAK is a multipiliated mutant with more pili than any of the strains reported herein, yet it has lower net hydrophobicity than any of the CF isolates and is resistant to nonopsonic phagocytosis (Cabral DA, Speert DP, unpublished observation). Other bacterial factors such as lipopolysaccharide, capsular antigens, and slime layers and host factors such as $\operatorname{IgG}, \operatorname{IgA}$, albumin, fibrinogen, and mucins can also alter bacterial hydrophobicity and effect susceptibility to phagocytosis. In addition exogenous factors such as various cationic polyamino acids have been shown to enhance nonopsonic phagocytosis of certain bacteria (12).

Acknowledgments. The authors thank David Monk and Martin Puterman for statistical analysis and Lisa Thorson for technical assistance.

\section{REFERENCES}

1. Wood RE, Boat TF, Doershuk CF 1976 Cystic fibrosis. Am Rev Res Dis 113:833-878

2. Baltimore RS, Mitchell M 1980 Immunologic investigation of mucoid strains of Pseudomonas aeruginosa: comparison of susceptibility to opsonic antibody in mucoid and nonmucoid strains. J Infect Dis 141:238-247

3. Ramphal R, Pier GB 1985 Role of Pseudomonas aeruginosa mucoid exopolysaccharide in adherence to tracheal cells. Infect Immun 47:1-4

4. Speert DP, Eftekhar F, Puterman ML 1984 Nonopsonic phagocytosis of strains of Pseudomonas aeruginosa from cystic fibrosis patients. Infect Immun 43:1006-1011

5. Speert DP, Loh BA, Cabral DA, Salit IE 1986 Nonopsonic phagocytosis of nonmucoid Pseudomonas aeruginosa by human neutrophils and monocytederived macrophages is correlated with bacterial piliation and hydrophobicity. Infect Immun 53:207-212

6. Wahba AH, Darrell JH 1965 The identification of atypical strains of Pseudomonas aeruginosa. J Gen Microbiol 38:329-342

7. Pier GB, DesJardins D, Aguilar T, Barnard M, Speert DP 1986 Polysaccharide surface antigens expressed by nonmucoid isolates of Pseudomonas aeruginosa from cystic fibrosis patients. J Clin Microbiol 24:189-196

8. Speert DP, Silverstein SC 1985 Phagocytosis of unopsonized zymosan by human monocyte-derived macrophages: maturation and inhibition by mannan. J Leuk Biol 38:655-658

9. Van Oss CJ, Gillman CF 1972 Phagocytosis as a surface phenomenon. J Reticuloendothel Soc 12:497-502

10. Schwarzmann S, Boring JR III 1971 Antiphagocytic effect of slime from a mucoid strain of Pseudomonas aeruginosa. Infect Immun 3:762-767

11. Oliver AM, Weir DM 1983 Inhibition of bacterial binding to mouse macrophages by pseudomonas alginate. J Lab Clin Immunol 10:221-224

12. Peterson PK, Gekker G, Shapiro R, Freiberg M, Keane WF 1984 Polyamino acid enhancement of bacterial phagocytosis by human polymorphonuclear leukocytes and peritoneal macrophages. Infect Immun 43:561-566 